\title{
Modelling People's Behaviour using Discrete-Event Simulation: A Review
}

\begin{tabular}{|r|l|}
\hline Journal: & International Journal of Operations and Production Management \\
\hline Manuscript ID & IJOPM-10-2016-0604.R4 \\
\hline Manuscript Type: & Research Paper \\
\hline Keywords: & $\begin{array}{l}\text { Literature review, Methodology for operations management, Performance } \\
\text { measurement, Process improvement }\end{array}$ \\
\hline \multicolumn{2}{|l}{} \\
\hline
\end{tabular}

SCHOLARONE

Manuscripts 


\title{
Modelling people's behaviour using discrete-event simulation: A review
}

\author{
Abstract \\ Purpose \\ The purpose of this paper is to provide a contribution to the area of behavioural operations \\ management by identifying key challenges in the use of discrete-event simulation (DES) to model \\ people's behaviour in Operations Management (OM).
}

\section{Design/methodology/approach}

A systematic literature review method is undertaken in order to assess the nature and scale of all publications relevant to the topic of modelling people's behaviour with DES in OM within the period 2005 to 2017.

\section{Findings}

The publications identified by the literature review reveal key challenges to be addressed when aiming to increase the use of DES to model people's behaviour. The review also finds a variety of strategies in use to model people's behaviour using DES in OM applications.

\section{Research limitations/implications}

A systematic literature review method is undertaken in order to include all publications relevant to the topic of modelling people's behaviour with DES in the OM domain but some articles may not have been captured.

\section{Originality/value}

The literature review provides a resource in terms of identifying exemplars of the variety of methods used to model people's behaviour using DES in OM. The study indicates key challenges for increasing the use of DES in this area and builds on current DES development methodologies by presenting a methodology for modelling people's behaviour in OM.

Keywords: behavioural operations, discrete-event simulation, human behaviour, simulation methodology, systematic literature review 


\section{Introduction}

Interest in behavioural operations management has a long history with Cummings (1977) stating that both behavioural and system constructs are crucial in studying, designing and evaluating production systems. Bendoly and Schultz (2006) present a special journal issue on the topic of incorporating behavioural theory in Operations Management (OM) empirical models. Within that journal issue an article by Bendoly et al. (2006) provide a review of papers published between 1985 and 2005 on behavioural research in operations management. They state that the success of the implementation of operations management tools and techniques, and the accuracy of its theories, relies heavily on our understanding of human behaviour. A 'follow on' special issue is presented in 2013 (Croson et al., 2013). Here the importance of the identification of individual differences, rather than the average response of people is emphasised. A further overview of behavioural operations management studies is provided in Zhao et al. (2013). Neumann and Dul (2010) report on an increasing interest in human issues in operations management and find through a systematic review of literature that operating system performance co-varies with the effects of human behaviour in $95 \%$ of studies that looked at both elements in human factor applications. Operations management areas such as lean management, with its related topics of mass customisation, flexibility and agility stress the very important role of the workforce, seen as a main asset and a source of competitive advantage (Liker and Convis, 2011). The modern workplace is characterised by frequent product and process change in addition to worker turnover and absenteeism. In this environment, workers must adapt to learn new tasks frequently, while at the same time responding to demand in the shortest possible time (Nembhard, 2014). Workers in these systems will have specific skills and a level of flexibility, which are highly individual qualities and the treatment of all employees as identical in terms of their manual skills, ability to learn and ability to cope with difficult situations is a major simplification (Malachowski and Korytkowski, 2016).

One way of studying the effect of human behaviour on operations performance is to use modelling techniques and the representation and prediction of human behaviour is seen by some authors as currently the most significant and unanswered modelling challenge (Taylor et al., 2015). However models have been criticized for their failure to attend to human aspects in the operations management domain. For example while recognising the essential role of simplification in model building, Boudreau et al. (2003) state that OM researchers and managers may not always be aware of the consequences these simplifications can have on decision making. Amongst the common assumptions used to represent people in $\mathrm{OM}$ models that can lead to omission of important features of the system are that people are not a major factor (many models look at machines without people, so the human side is omitted entirely), people are deterministic and predictable, people have perfect availability (no breaks, absenteeism, etc.), task times are deterministic, mistakes do not happen, or mistakes occur randomly and workers are identical (work at the same speed, have the same values, and respond to the same incentives) (Boudreau et al., 2003). Dode et al (2016) found that models that do not include human aspects may provide unreliable results in terms of productivity and quality estimates. However it is clear that it is difficult for humans to model themselves for a number of reasons which include the fact that people are complex entities that generate various behaviours that are often context dependent and people acting as modellers often have constrained understanding, knowledge and data about themselves, about the modelling context and about related causal impacts (Ajaefobi et al. 2010). 
One technique that has shown the capability to model human behaviour in OM systems is that of Discrete-Event Simulation. One example of this is in Nembhard (2014) who states that simulation is used to study a dynamic workplace due to the extreme complexity of using closed form analytical models. Discrete-Event Simulation (DES) (Pidd, 2006; Robinson, 2014) is widely used in the design of manufacturing (Greasley, 2005) and service operations (Shi et al., 2015). Simulation offers a way to investigate the behaviour of complex systems, and through the building of computer models and what-if experimentation, to explore and better understand the system behaviour (Kelton et al., 2007). There are a number of different approaches to simulation, including System Dynamics (SD) (Sterman, 2000, Morecroft, 2007), Agent Based Modelling (North and Macal, 2007) and Discrete Event Simulation (Kelton et al., 2007). Discrete Event Simulation involves building models of systems that consist of a number of building blocks including processes, entities and resources (Pidd, 2006) and so is particularly suited to the process orientation of OM.

The need for DES studies to include the modelling of human behaviour in OM systems has been recognised for some time with for example Juran and Schruben (2004) reporting the need for DES to incorporate accurate representations of individual worker behaviour in highly technical industries such as semiconductor manufacturing and service industries such as banking. However in 2004 Baines et al. (2004) found that human aspects were rarely included in DES studies and can been seen as the 'missing link' in manufacturing simulation. Hudlicka and Zacharias (2005) found that the standard approach in DES to modelling people is to model nominal behaviour, resulting in simulations that can be highly predictable across distinct situations and uniform across individuals. More recently Nembhard (2014) remarks how simulation studies in OM still commonly base their findings on a homogeneous and hypothetical workforce and presents a DES of a heterogeneous population informed by an empirically measured workforce. A systematic literature review of articles that have used DES to model human behaviour in OM since the 'missing link' article of Baines covering the years 2005-2017 is undertaken to assess the nature and scale of articles published in this area and to identify challenges to the wider use of DES to model human behaviour in OM.

\section{Method}

Current reviews of the use of simulation are usually based within an application domain such as manufacturing (Negahban and Smith, 2014) or focus on a specific application (Gul and Guneri, 2015). In order to provide an overview of the nature and scale of articles presenting the use of DES to model people's behaviour in OM, and due to the lack of any current reviews of this nature, a systematic literature search was performed using the Scopus, ScienceDirect, Google Scholar and Emerald Insight databases. To focus on contemporary implementations of discrete-event simulation it was decided a priori that the search would be restricted to studies from 2005 to 2017 . The identified keyword terms simulat* in combination with either discrete-event or discrete event was searched to identify studies in the domain of discrete-event simulation. These keywords were combined with the keyword terms human*, people, person, individual* to identify discrete-event simulation studies in the domain of modelling people's behaviour. Papers were filtered for relevance to the field of $\mathrm{OM}$ and providing simulation model implementation details by title and then at abstract and article level in accordance with inclusion and exclusion criteria (see table 1).

Take in Table 1 Inclusion and exclusion criteria for the studies reviewed 
The review of titles, abstracts and articles was undertaken independently by the authors of this article during January and February 2017 and January 2018 to ensure validity. The review follows the Preferred Reporting Items for Systematic reviews and Meta-Analysis (PRISMA) guidelines (Moher et al., 2009) and the procedure is shown in figure 1.

Take in Figure 1 PRISMA flow diagram illustrating the literature review procedure

The inclusion criteria restrict articles to those that demonstrate the use of DES to model the effect of human behaviour on performance in the area of operations management and provide details of an application of this with reported results. This is to enable an analysis to be made of the actual methods employed to model human behaviour in the context of a DES study which could be placed within an application framework. The exclusion criteria (numbered 1 to 5) are shown in brackets in figure 1 and can be cross-referenced with the criteria numbered in table 1. Exclusion criteria number 4 concerns a particular type of article that was excluded on the basis that it modelled outcomes in terms of human performance itself rather than the effect of human behaviour on operations performance. These articles generally use task analysis conducted using the Micro Saint DES which may be embedded in human performance modelling tools such as the Improved Performance Research Integration Tool (IMPRINT), the Man-Machine Integration Design and Analysis System (MIDAS) and the Integrated Performance Modeling Environment (IPME) (Harriott and Adams, 2013). Thus the literature review found 29 articles that met the criteria filtered from an original search count of 4401. These articles are listed in table 2.

Take in Table 2 Articles reporting on the use of DES to model people's behaviour (2005-2017)

In terms of a statistical analysis of the review results it is apparent that there are relatively few applications of DES that model people's behaviour in the literature. Figure 2 shows the distribution of the articles presented in table 2 over the publication years 2005-2017. Although each year has at least one publication the level of publication output is generally low throughout the publication period covered. One reason for this low level of publication is due to the strict criteria of the literature review of requiring implementation details of the model within the papers selected which is essential in order to conduct a critical assessment of the methods used to model people's behaviour. The lack of detail in documentation of discrete event simulation modelling efforts reported in the literature and its implications for reproducible research is discussed in Uhrmacher et al. (2016).

Take in Figure 2 Articles of Modelling People's Behaviour using DES by Year

\section{Findings}

In order to assess how people's behaviour was modelled using DES within the articles identified by the literature review we need to consider the initial phases of the simulation study process. Once the modeller has gained an understanding of the problem situation they will need to determine the simulation study objectives. These objectives then lead to the design of a conceptual model which provides a specification for the data requirements of the different areas of the model such as customer arrivals and process times. In a traditional simulation study methodology these data requirements do not consider the issue of modelling people within the model specifically. Here we 
use these generic definitions of the areas of data requirements and relate them to the areas in which we can model people's behaviour. Thus based on the data requirements of a simulation model defined in Greasley (2004) the aspect of people's behaviour we may wish to model can be classified as following:

- Modelling People's Decisions (Decision Points) : Logic data defining the process flow undertaken by people in the model including decision points. Decision points may be modelled using conditional (if.. then, else) rules or probability distributions.

- Modelling People's Availability (Resource Availability) : This defines the availability of a person over time, such as a work schedule.

- Modelling People's Task Performance (Process Timing) : Process or task durations which define the time taken by a person to undertake a task.

- Modelling People's Arrivals (Demand Pattern) : The arrival rate of people into the simulation, such as customer arrivals.

- Modelling People's Movement (Process Routing) : The movement of people through the process represented in an animated display.

Each article from the literature review is now placed within one or more of the modelling area categories defined above and a critical assessment made of the implementation focusing on the data requirements challenges in these areas.

\section{Modelling People's Decisions}

Four articles have been identified that model people's decisions from the literature review. Here no cognitive models are employed so the main issue is the codification of the decision process. This is generally achieved using data gathered from observation and interviewing of the decision makers involved. For example Elliman et al. (2005) codify 'at-will' tasks (tasks for which people can decide themselves on the sequence that they are attempted) by the use of variables that were related to the task itself (for example task deadline) but also to organisational variables such as the importance of the customer of the task. Majid and Herawan (2013) codify the proactive behaviour of staff in a customer processing system. The speeding up of service is triggered by the appearance of long customer queues. Hannah and Neal (2014) treat the decision process as a 2-stage process with tasks selected for execution but then considered for either immediate execution or deferral until a later time depending on variables such as workload and time to deadline. Finally Kokkinou and Cranage (2011) use an online scenario-based survey to identify relevant variables and derive a regression equation for the choice between self-service or manual service in a hotel check-in process. The authors cite the use of an online survey design as a relatively inexpensive and fast way to collect data on customer preferences before implementation of a system.

Modelling People's Availability 
Two articles were identified as modelling people's availability in the literature review. A relatively straightforward approach was taken by Lassila et al. (2005) who used a theoretical distribution to represent the unavailability of workers due to off-station work tasks or not work related activities. Neumann and Medbo (2009) (earlier version in Neumann et al., 2006) consider operators work autonomy and operators work capacity (ability to work at a standard pace). Autonomy is postulated as the ability to take breaks (which occur randomly) with low autonomy equal to $20 \%$ of rest breaks taken when desired and high autonomy equal to $100 \%$ of rest breaks taken when desired. The authors note that validating this relationship requires a field experiment that remains for future research.

\section{Modelling People's Task Performance}

The area of task performance dominates the articles found by the literature review with 19 from 29 articles in this category.

A number of articles presented implementations that gather data on operator performance in order to provide sample data for a task time theoretical distribution. For example Mason et al. (2005) collect empirical data on operator performance using an automated measurement system within a factory and then use curve fitting software to fit a distribution to the activity data. Kozine (2007) (previously in Kozine, 2006) investigates the probability of task (action) failure at a Nuclear power plant. The data collection method is not defined but the task duration is modelling using an exponential distribution and the successful completion of a task within a set time is viewed as a consequence of the ability of the person and the demands of the task. Silva et al. (2014) models the variation in performance of assembly line operators which uses empirical data regarding each operator's performance. Whilst the majority of studies required the instigation of data collection activities for the model this investigation was enabled by the use of current data held by the company on a database. Perez et al. (2015) and Neumann and Medbo (2017) both model variation in cycle times of factory operations using a gamma distribution as suggested by Law and Kelton (1991) as being appropriate for modelling manual work. Shewchuk et al. (2017) collect data using observation and video recording for use in distributions to represent activity times in a multi-worker construction process. McHaney (2008) provides a method of modelling personas which are fictionalised descriptions of people using archetypes of people's behaviour. The collection of data through observation at the archetype level of abstraction provides a way of improving model accuracy without the need to collect data at the individual level.

Rather than using a theoretical distribution to represent task times a number of articles presented implementations that collected data on a range of variables that were used within a mathematical equation to represent worker tasks time. For example Nehme et al. (2008) simulated differences in operator performance using a parabolic function that relates operator utilisation to performance. Khalil and Weston (2009) model worker performance as the multiplication of worker accuracy (percentage of successfully completed jobs) and worker speed (rate of jobs completed). Nembhard (2014) models cross-training policies using empirical data collected by observation that is used to parameterise an equation of individual worker learning and forgetting. It was found that a number of articles make use of learning curve equations but again approaches differ in terms of the parameters of the equations and the context in which they are used. These include Ilar (2008) who studies the impact of worker competence on productivity in a highly automated press line. Neumann 
and Medbo (2017) assess the effect of 3 levels of learning rate on operator performance. All operators are assumed to have the same learning rate and the authors note that there is little data available on inter-individual learning rate variability in assembly work. Wang et al. (2013) collect empirical data related to variables such as experience, age and dexterity which are used as parameters for a worker's performance. Dode et al. (2016) model the learning effect at a workstation level rather than at the individual worker level. Malachowski and Korytkowski (2016) model multiple skilled operators on a production line by the use of a set of competences required at each workstation to each of which is assigned a different learning curve. The article shows how work experience on one working post translates into performance on other posts, thus enabling better workforce scheduling.

The next approach is to use empirical data applied to models of human behaviour. For example Plott (2006) uses empirical data from human factors and material handling literature so that the impact of excessive work stress on decreasing productivity (i.e. task time) could be modelled. Kazmierczak et al. (2007) use a variety of data collection methods including the use of video recording of operator actions. As with Plott (2006) the main focus of the article is regarding physical aspects of performance but again behavioural factors were incorporated into the analysis including level of operator experience, operator cycle time at work stations and cycle time variation at work stations. Colombi and Ward (2010) use Human Computer Interaction ( $\mathrm{HCl}$ ) models to assess the surveillance time for people when controlling unmanned aircraft from a computer terminal. Ajaefobi et al (2010) model the effect of the competence of operators in a manufacturing plant. A standard mix of basic, practitioner and expert operators are compared to a system with expert operators only.

Finally one example is presented of the use of a cognitive model of human behaviour. Riedel et al. (2009) model human competence based on the PSI theory (Detje and Kuenzel, 2003). Task performance in modelled over time showing how competence oscillates dependent on experienced success and failure at a new task. This approach provides an alternative to the traditional learning curve effect which implies a continuous improvement over time without any setbacks in performance due to failures.

\section{Modelling People's Arrivals}

Two articles were identified as modelling people's arrivals in the literature review. Knight et al. (2012) attempt to codify the decision of individual patients when choosing a hospital unit to attend and deciding whether to actually attend that hospital. The decision is codified using hospital reputation, waiting list at the hospital, travel distance to that particular hospital from a demand node and level of irrational attraction or repulsion of a patient for a particular hospital unit. Brailsford et al. (2012) (previous version is in Brailsford et al., 2006) however employs a cognitive modelling approach in the form of the Theory of Planned Behaviour (TPB) cognitive model (Ajzen, 1991) to predict attendance for breast cancer screening sessions. The TPB takes empirical data on demographic variables and personality traits and transforms these to attitudes towards behaviour, subject norms and perceived behavioural control.

Modelling People's Movement 
Two articles were identified as modelling people's movement in the literature review. Dubiel and Tsimhomi (2005) present a DES model in Automod which provides an animation of a theme-park where people interact with objects and other people in their environment to get directions and then walk or take a tram to their final destination. Robinson (2015) presents a DES model on the platform of the Excel spreadsheet with the simulation coded in the embedded Visual Basic for Applications (VBA) programming software. Customers move across a grid using a shortest path rule (expressed as an equation). The article states that the approach used is arguably a mixed DES/ABS model and Dubiel and Tsimhoni (2005) also describe their implementation as an hybrid approach in which an agent-based module within the discrete-event simulation environment is used to model the movement of people.

\section{Discussion}

An important outcome of the review is the identification of a number of articles published presenting implementations of the modelling of people's behaviour. These articles cover modelling using DES in all the main areas of a model requiring data collection. The papers also cover many aspects of people's behaviour in operations including the modelling of stress, physical tiredness, competence, attendance, skill levels, capability and flexibility. In order to facilitate the incorporation of people's behaviour in OM models there now follows a discussion regarding the nature of the cost and workload required when modelling human behaviour. Key challenges will then be discussed in the areas of data collection needs and validation requirements for a DES when modelling human behaviour. There then follows a categorisation of the articles found and a methodology is presented to guide the use of DES to model people's behaviour in OM.

As stated in the introduction the ability to model people's behaviour provides an ability to avoid abstracting away people's differences and thus provide a more accurate model for prediction. The abstraction level or level or detail in the model should be based on the study objectives. This can be considered in terms of does the human behaviour affect the goals (output variables) to a sufficient degree that they require consideration in the model? In fact Mason et al. (2005) found that when dealing with larger models with complex system dynamics it is difficult to predict whether the inclusion of people's behaviour will have a significant effect on overall performance or not. However as well as the study objectives there is also a need to consider the effort required to incorporate the modelling of people in the DES in relation to the gains obtained from doing so. In terms of this Bruzzone et al. (2007) discuss the need when contemplating modelling human behaviour to evaluate the modelling impact in terms of cost and workload to introduce these aspects. Within the literature review Ilar (2008) judges an approach suggested (but not implemented) by Baines and Benedettini (2007) might be too complex to be industrially applicable and puts forward a more straightforward method which in their view offers most of the advantages with much less effort. Hannah and Neal (2014) provide a highly simplified representation of the tasks undertaken by people but determine that the level of abstraction is appropriate for the aims of the study. This trade-off between meeting simulation study objectives against the cost and effort of doing may be resolved by adjusting the conceptual model specification in an iterative process until a feasible solution is found (Robinson, 2014). This process is likely to be particularly important in DES studies that incorporate human behaviour because of challenges in two areas. 
The first challenge apparent from the literature review is the extensive data collection requirements that are often required when modelling human behaviour. A detailed outline of the enhanced data requirements necessary for modelling people's behaviour is provided by Kazmierczak et al (2007) who used a combination of data collection methods including document analysis, semistructured group interviews, observation and activity analysis of video recordings. Elliman et al (2005) found that decision-making by knowledge workers (who had discretion over the timing and duration spent on tasks) was complex and based on many factors such as other work commitments implying extensive data collection needs. Some authors presented approaches to limit data collection requirements. For example Neumann and Medbo (2009) operationalised the autonomy of individuals as their ability to take breaks at will from their duties. Two scenarios of high and low autonomy were modelled. This approach limits the need for data collection by using task and environmental variables, rather than individual characteristics to model individual behaviour. McHaney (2008) suggests the use of archetypes to model groups of people who display similar behaviour and so avoid collection of data on behaviour at an individual level. When making customer decisions in service systems Kokkinou and Cranage (2011) make use of an on-line survey to quickly collect data on customer preferences. Finally in most cases simulation practitioners will need to initiate data collection activities but Silva et al. (2014) were able to use current data of people's performance held in a company database.

The second challenge when modelling people's behaviour, apparent from the literature review, is the difficulty of ensuring model validation. Model validation relates to the idea that the model is wholly adequate and appropriate for the task for which it is intended. Simple though this notion of validation may sound, in practice it can be very difficult to validate a simulation model properly (Pidd, 2006). In terms of validating models that incorporated the behaviour of people a number of authors recognized the difficulty of this process. For example Neumann and Medbo (2009) found difficulty in obtaining empirical evidence to validate the operationalization of human behaviour in their model and suggest the need for field research to provide this validation. They did however find they could study the interaction effect between multiple human factors by using a factorial approach to the simulation experimental design. Colombi and Ward (2010) suggested that the effectiveness of their model could have been improved with additional validation to the real system. Hannah and Neal (2014) used data collected from the behaviour of just two people for their model and recognized the challenge of generalizing the model across different people and different work environments. There are particular challenges when using and validating a DES that uses a cognitive model as in Brailsford et al. (2012) who was able to undertake a validation exercise by comparing simulation results to historical data. The TPB model used in Brailsford et al. (2012) has been widely applied but the challenge in the use of cognitive models is that they are often not validated for a particular implementation context such as an OM system (Silverman et al., 2003).

Notwithstanding the above challenges the articles presented show that modelling human behaviour using DES in OM is feasible and can lead to more accurate model results. However it is apparent from the literature that there are a number of modelling strategies for achieving this. We will now define these strategies by introducing the categories of modelling approach and modelling method.

Figure 3 outlines the modelling approaches of 'scenario', 'impact' and 'individual'. Each approach is related to a level of abstraction and data requirements when modelling people's behaviour. 
Take in Figure 3 Approaches to modelling people's behaviour

The scenario approach considers the effect of people 'outside' of the model by observing model results under a range of scenarios. Using this approach people's behaviour is codified into a model input variable. For example worker capacity is set to 'normal' or 'low' in Neumann and Medbo (2009) and a scenario run for each value of the variable. The approach is related to DES studies when data is not available for collection and is treated as an experimental factor rather than a fixed parameter. As Robinson (2014) states this approach can only be applied when there is some control over the data in question. The remaining approaches to modelling people in a DES are termed impact and individual (figure 4) and are implemented 'inside' the model.

Take in Figure 4 Modelling People's behaviour 'inside' the model by impact and individual approaches

The effect of people's behaviour on system performance can be modelled with the use of impact variables that relate to the task that the person is undertaking or to organizational variables that impinge on a person's performance. An example would be to use the impact variable of 'task deadline' to prioritise tasks for processing by a worker in an office as in Elliman et al (2005). In this example data collection is required in terms of the impact variable but it is not necessary to collect data on individual behaviour regarding the decision of task priority. This approach can reflect organizational policies but if individuals have discretion in their work practices their individual preferences are not reflected using this method. If we do wish to assess the effect of individual characteristics on performance then we will need to model these individual differences within the model itself. Using the 'individual' approach the characteristics of people are used to distinguish the differences in behaviour between different people (termed 'across' differences) or differences in behaviour of an individual over time (termed 'within' differences). An example of an across difference is competence level at an operation which will differ across people (for example Malachowski and Korytkowski (2016)). A within difference would be an increase in operating performance of an individual over time such as due to learning effects (for example Nembhard (2014)).

Modelling method strategies can either be data driven to predict human behaviour or cognitive architectures to simulate human mental processes (Campbell and Cannon-Bowers, 2000). Data driven methods comprise deriving a theoretical distribution which is similar to standard practice in a simulation study but using data based on human behaviour (for example Mason (2005) and Lassila et al. (2005)), constructing a mathematical equation such as a learning curve equation (for example Nembhard (2014), Dode et al. (2016) and Malachowski and Korytkowski (2016)) or the direct use of empirical data (for example Ajaefobi et al. (2010), Wang et al. (2013)). Cognitive architectures used to represent the cognitive process include the Physical, Emotional, Cognitive and Social architecture (PECS) (Schmidt, 2000) and Theory of Planned Behaviour (TPB) (Ajzen, 1991) (for example Riedel et al. (2009), Brailsford et al. (2012)).

Table 3 summarises the literature review findings and classifies the papers by modelling method used within each modelling area and modelling approach. These studies should be considered as exemplars rather than prescriptions on the best method to use for a particular modelling area and modelling approach. Indeed in some areas there are exemplars offering a choice of different methods and in some areas no examples have been found from the literature at present. 
However an area which shows no current examples does not imply that they could not be appropriate options for a study.

Take in Table 3 Methods of Modelling People's behaviour categorised by Modelling Area and Modelling Approach

In order to guide the user when modelling people's behaviour figure 5 presents a methodology for modelling people's behaviour based on a development of current DES methodologies presented in Law (2014) and Banks et al. (2014).

Take in Figure 5 A Methodology for Modelling People's Behaviour in DES

Here simulation objectives are identified which lead to a conceptual model containing a detailed specification of the model requirements. At this stage the user is guided to make choices for modelling people's behaviour in terms of modelling area, then choice of modelling approach and finally choice of modelling method. The current exemplars can be considered from table 3 which may provide useful guidance in these choices.

At this point we need to assess the feasibility in terms of effort and cost of data collection requirements for the particular modelling aspect chosen. As identified by the literature review this is a key challenge in the model development process and may require that the conceptual model specification be adjusted and a reassessment of the modelling area, approach and method used for modelling people's behaviour. This could mean implementing model simplification strategies (Robinson, 2014) to reduce the scope and level of detail required in the model. This could then remove the need to model some aspects of human behaviour or to replace for example an 'individual' modelling approach by a 'scenario' or 'impact' approach which require less demanding data collection needs. The next stage of a traditional simulation methodology is to build the simulation model and to check for coding errors termed verification.

Once verified the validation stage is to ensure that the model represents the real system adequately in terms of meeting the simulation study objectives. This represents the second challenge for representing people's behaviour and if validation cannot be ensured could again involve the redefinition of the conceptual model and a reassessment of the modelling area, approach and method used for modelling people's behaviour. Once validated the DES model can then be used for experimentation and presentation of results.

\section{Conclusions}

Bendoly and Prietula (2008) discuss how modelling the behavioural dynamics observable among real humans in various tasks emblematic of OM practice can help refine, occasionally support and, often refute past modelling assumptions and hence present essential contributions that truly can help close gaps between operations research and effective management practice. This article aims to advance the incorporation of behavioural responses in OM models by providing the following contributions. It brings together a record of the publications that demonstrate the use of DES to model people's behaviour in the OM domain. These publications show the relative scarcity of research in this area. This can be seen as due to the lack of model implementation detail provided in the literature and to the major challenges faced when modelling people's behaviour in the areas of 
data collection and model validation. The review also found a number of different strategies employed when modelling people's behaviour using simulation and the article presents a new perspective in terms of a methodological approach to making a choice between these strategies in the context of the cost and effort required to implement them.

In terms of further work it is apparent that additional publications are needed of modelling people's behaviour using DES which provide sufficient implementation detail to act as exemplars for future efforts in this area. Further work is also needed to provide an assessment of the modelling strategies identified in the literature review. For example a comparison could be made between the use of learning curve equations and cognitive models to represent people's learning behaviours in a particular modelling area at a certain level of required detail. This would require case studies making a critical comparative assessment of these methods in areas such as the effort required in data collection and the improvement in model accuracy. Finally there is an extended literature on cognitive models of human behaviour in areas such as organisational behaviour, defence and health systems and work is needed to apply and test these models for use in an OM context.

In terms of limitations this article is based on a systematic literature review method that although made every effort to include all publications relevant to the topic of modelling people's behaviour with DES in OM, some articles may not have been captured. Furthermore, the process of evaluation and interpretation of the articles is reliant on the academic judgement of the author team.

\section{References}

Ajaefobi, J., Weston, R., Wahid, B., Rahimifard, A. (2010), "Integrated approach to modelling human systems as reuseable components of manufacturing workplaces", International Journal of Computer Integrated Manufacturing, Vol. 23 No. 3, pp. 195-215.

Ajzen, A. (1991), "The theory of planned behaviour", Organizational Behaviour and Decision Processes, Vol. 50, pp. 179-211.

Baines, T. and Benedettini, O. (2007), "Modelling of human performance within manufacturing systems design: from theoretical towards practical framework", Journal of Simulation, Vol. 1 No. 2, pp. 121-130.

Baines, T., Mason, S., Siebers, P. and Ladbrook, J., (2004), "Humans: the missing link in manufacturing simulation?" Simulation Modelling Practice and Theory, Vol. 12, pp. 515-526.

Banks, J., Carson II, J.S., Nelson, B.L., Nicol, D.M. (2014), Discrete-Event System Simulation, $5^{\text {th }}$ Edition, Pearson Education Limited, Harlow.

Bendoly, E. and Prietula, M. (2008), "In "the zone": The role of evolving skill and transitional workload on motivation and realized performance in operational tasks", International Journal of Operations and Production Management, Vol. 28, No. 12, pp. 1130-1152.

Bendoly, E. and Schultz, K.L. (2006), "Incorporating behavioural theory in OM empirical models", Journal of Operations Management, Vol. 24, pp. 735-736 (Special issue).

Bendoly, E., Donohue, K. and Schultz, K.L. (2006), "Behavior in operations management: Assessing recent findings and revisiting old assumptions", Journal of Operations Management, Vol. 24, pp. 737-752.

Boudreau, J., Hopp, W., McClain, J.O., Thomas, L.J. (2003), “On the Interface between Operations and Human Resources Management", Manufacturing and Service Operations Management, Vol. 5 No. 3, pp. 179202.

Brailsford, S.C., Harper, P.R. and Sykes, J. (2012), "Incorporating Human Behaviour in simulation models of screening for breast cancer", European Journal of Operational Research, Vol. 219, pp. 491-507. 
Brailsford, S.C., Sykes, J. and Harper, P.R. (2006), "Incorporating Human Behaviour in Healthcare Simulation Models", Proceedings of the 2006 Winter Simulation Conference, pp. 466-472.

Bruzzone, A.G., Briano, E., Bocca, E. and Massei, M. (2007), "Evaluation of the impact of different human factor models on industrial and business processes", Simulation Modelling Theory and Practice, Vol. 15, pp. 199-218.

Campbell, G. E. and Cannon-Bowers, J. A. (2000), "The application of human performance models in the design and operations of complex systems", Proceedings of the Human Factors and Ergonomics Society, Vol. 44 No. 6, pp. 733-736.

Colombi, J.M. and Ward, J.R. (2010), "Human systems integration: A discrete event simulation of operational utility for control of multiple small unmanned aerial systems", Proceedings of the Human Factors and Ergonomics Society, Vol. 3, pp. 2145-2149.

Croson, R., Schultz, K., Siemsen, E., Yeo, M.L. (2013) "Behavioral operations: The state of the field", Journal of Operations Management, Vol. 31, pp. 1-5.

Cummings, L.L. (1977), "Needed Research in Production/Operations Management: A Behavioral Perspective", Academy of Management Review, Vol. 2 No. 3, pp. 500-504.

Detje, F. and Kuenzel, J. (2003), "PSI - An architecture of human action and intention regulation", Proceedings of the Fifth International Conference on Cognitive Modelling (ICCM 2003), Bamberg.

Dode, P., Greig, M., Zolfaghari, S. and Neumann, W.P. (2016), "Integrating human factors into discrete event simulation: a proactive approach to simultaneously design for system performance and employees' well being", International Journal of Production Research, Vol. 54 No. 10, pp. 3105-3117.

Dubiel, B. and Tsimhoni, O. (2005), "Integrating Agent Based Modeling into a Discrete-Event Simulation", Proceedings of the 2005 Winter Simulation Conference, pp. 1029-1037.

Elliman, T., Eatock, J. and Spencer, N. (2005), "Modelling knowledge worker behaviour in business process studies", The Journal of Enterprise Information Management, Vol. 18 No. 1, pp. 79-94.

Greasley, A. (2005), "Using system dynamics in a discrete-event simulation study of a manufacturing plant", International Journal of Operations and Production Management, Vol. 25, No. 6, pp. 534-548.

Greasley, A. (2004) Simulation Modelling for Business, Ashgate Publishing Ltd., Aldershot.

Gul, M. and Guneri, A.F. (2015), "A comprehensive review of emergency department simulation applications for normal and disaster conditions", Computers and Industrial Engineering, Vol. 83, pp. 327-344.

Hannah, S.D. and Neal, A. (2014), "On-The-Fly Scheduling as a Manifestation of Partial-Order Planning and Dynamic Task Values", Human Factors, Vol. 56 No. 6, pp. 1093-1112.

Hudlicka, E. and Zacharias, G. (2005), "Requirements and Approaches for Modeling Individuals within Organizational Simulations" In Organizational Simulation (Rouse, W.B. and Boff, K.R.) John Wiley and Sons Inc., New Jersey.

Ilar, T.B.E. (2008), "A simplified modelling approach for human system interaction", Proceedings of the 2008 Winter Simulation Conference, SCS, pp. 903-908.

Juran, D.C. and Schruben, L.W. (2004), "Using worker personality and demographic information to improve system performance prediction", Journal of Operations Management, Vol. 22, pp. 355-367.

Kazmierczak, K., Neumann, W.P. and Winkel, J. (2007), "A case study of serial-flow car disassembly: ergonomics, productivity, and potential system performance", Human Factors and Ergonomics in Manufacturing, Vol. 17 No. 4, pp. 331-351.

Kelton, D., Sadowski, R. and Sturrock, D. (2007) Simulation with Arena, McGraw-Hill, New York.

Khalil S.N. and Weston R.H. (2009), "Modelling human resource systems in support of efficient production", IFIP Advances in Information and Communication Technology, Vol. 322, pp. 72-79

Knight, V.A., Williams, J.E. and Reynolds, I. (2012), "Modelling patient choice in healthcare systems: development and application of a discrete event simulation with agent-based decision making", Journal of Simulation, Vol. 6, pp. 92-102.

Kokkinou, A. and Cranage, D.A. (2011), "Modeling Human Behaviour in Customer-Based processes: The Use of Scenario-Based Surveys", Proceedings of the 2011 Winter Simulation Conference, SCS, pp. 683-689. 
Kozine, I. (2006), "Simulation of human performance in a discrete event environment" ${ }_{2}$ Proceedings of the European Safety and Reliability Conference 2006, ESREL 2006 - Safety and Reliability for Managing Risk, 1, pp. 355-362.

Kozine, I. (2007), "Simulation of human performance in time-pressured scenarios", Proc. IMechE Vol. 221 Part O: J. Risk and Reliability, pp. 141-151.

Lassila, A.M., Saad, S.M., Perera, T., Koch, T. and Chrobot, J. (2005), "Modelling and Simulation of HumanCentred Assembly Systems - A Real Case Study", IFIP Advances in Information and Communication Technology, Vol. 159, pp. 405-412.

Law, A.M. (2014), Simulation Modeling and Analysis, $5^{\text {th }}$ Edition, McGraw-Hill Education, New York.

Law, A.M. and Kelton, D.W. (1991), Simulation Modeling and Analysis, McGraw-Hill, New York.

Liker, J.K. and Convis, G.L. (2011), The Toyota way to lean leadership. McGraw-Hill, New York.

Majid, M.A. and Herawan, T. (2013), "Modelling Reactive and Proactive Behaviour in Simulation: A Case Study in a University Organisation", International Journal of Multimedia and Ubiquitous Engineering, Vol. 8, No. 6, pp. 329-338.

Malachowski, B. and Korytkowski, P. (2016), "Competence-based performance model of multi-skilled workers", Computers and Industrial Engineering, Vol. 91, pp. 165-177.

Mason, S., Baines, T., Kay, J.M. and Ladbrook, J. (2005), "Improving the Design Process for Factories: Modeling Human Performance Variation", Journal of Manufacturing Systems, Vol. 24 No. 1, pp. 47-54.

McHaney, R.W. (2008), "Use cases and personas: uses in service sector simulation development", Int. J. Simulation and Process Modelling, Vol. 4, Nos. 3/4, pp. 264-279.

Moher, D., Liberati, A., Tetzlaff, J., Altman, D.G. and The PRISMA Group (2009), "Preferred Reporting Items for Systematic Reviews and Meta-Analyses: The PRISMA Statement", PLoS Medicine, Vol. 6 No. 7, pp. 1-6.

Morecroft, J. (2007), Strategic Modelling and Business Dynamics, Chichester, John Wiley and Sons, England.

Nagahban, A. and Smith, J.S. (2014), "Simulation for manufacturing system design and operation: Literature Review and Analysis", Journal of Manufacturing Systems, Vol. 33, No. 2, pp. 241-261.

Nehme, C., Crandall, J.W. and Cummings, M.L. (2008), “Using Discrete-Event Simulation to Model Situational Awareness of Unmanned-Vehicle Operators", Virginia Modelling, Analysis and Simulation Center Capstone Conference.

Nembhard, D.A. (2014), “Cross training efficiency and flexibility with process change”, International Journal of Operations and Production Management, Vol. 34 No. 11, pp. 1417-1439.

Neumann, W.P. and Dul, J. (2010), "Human factors: spanning the gap between OM and HRM", International Journal of Operations and Production Management, Vol. 30 No. 9, pp. 923-950.

Neumann, W.P. and Medbo, P. (2017), "Simulating operator learning during production ramp-up in parallel vs. serial flow production", International Journal of Production Research, Vol. 55, No. 3, pp. 845-857.

Neumann, W.P. and Medbo, P. (2009), "Integrating human factors into discrete event simulations of parallel flow strategies", Production Planning and Control, Vol. 20 No. 1, pp 3-16.

Neumann, W.P., Winkel, J., Medbo, L., Magneberg, R. and Mathiassen, S.E. (2006), "Production system design elements influencing productivity and ergonomics: A case study of parallel and serial flow strategies", International Journal of Operations and Production Management, Vol. 26 No. 8, pp. 904-923.

North, M. \& Macal, C. (2007), Managing Business Complexity, Oxford University Press, New York.

Perez, J., de Looze, M.P., Bosch, T. and Neumann, W.P. (2014), "Discrete event simulation as an ergonomic tool to predict workload exposures during systems design", International Journal of Industrial Ergonomics, Vol. 44, pp. 298-306.

Pidd, M. (2006), Computer Simulation in Management Science, Fifth Edition, John Wiley and Sons Ltd., Chichester.

Plott, B. (2006), "Using discrete event simulation to assess human lifting and assembly of vehicle armor", Proceedings of the Human Factors and Ergonomics Society, pp. 1751-1754.

Riedel, R., Mueller, E., Von Der Weth, R. and Pflugradt, N. (2009), "Integrating human behaviour into factory simulation - A feasibility study", IEEM 2009 - IEEE International Conference on Industrial Engineering and Engineering Management, pp. 2089-2093. 
Robinson, S. (2014), Simulation: The practice of model development and use, $2^{\text {nd }}$ edition, John Wiley and Sons Ltd., Chichester.

Robinson, S. (2015), "Modelling without queues: adapting discrete-event simulation for service operations", Journal of Simulation, Vol. 9, pp. 195-205.

Schmidt, B. (2000), The Modelling of Human Behaviour, SCS Publications, Erlangen.

Shewchuk, J.P., Nussbaum, M.A., Kim, S. and Sarkar, S. (2017), "Simulation Modeling and Ergonomic Assessment of Complex Multiworker Physical Processes, IEEE Transactions on Human-Machine Systems, Vol. 47, No. 6, pp. 777-788.

Shi, J., Erdem, E., Peng, Y., Woodbridge, P., Masek, C. (2015), "Performance analysis and improvement of a typical telephone response system of VA hospitals: A discrete event simulation study", International Journal of Operations and Production Management, Vol. 35, No. 8, pp. 1098-1124.

Silva, E. , Donauer, M. , Azevedo, A , Pecas, P. , Henriques, E. (2014), “A case study evaluating the impact of human behaviour on a manufacturing process in-line with automatic processes by means of a simulation model", IEEE International Conference on Industrial Engineering and Engineering Management, pp. 145-149.

Silverman, B.G., Cornwell, J. and O’Brien, K. (2003). Human Performance Simulation in Ness, J.W., Rizer, D.R., \& Tepe, V. (eds) Metrics and methods in human performance research toward individual and small unit simulation, Human Systems Information Analysis Centre: Washington DC.

Sterman, J. (2000), Business Dynamics, McGraw-Hill.

Taylor, S.J.E., Khan, A., Morse, K.L., Tolk, A., Yilmaz, L., Zander, J. and Mosterman, P.J. (2015), “Grand challenges for modelling and simulation: simulation everywhere - from cyberinfrastructure to clouds to citizens", Simulation: Transactions of the Society of Modeling and Simulation International, Vol. 91 No. 7, pp. 648-665.

Uhrmacher, A.M., Brailsford, S., Liu, J., Rabe, M. Tolk, A. (2016), "Panel - Reproducible research in discreteevent simulation - A must or rather a maybe?", Proceedings of the 2016 Winter Simulation Conference, SCS, pp. 1301-1315.

Wang Q. , Sowden M. , Mileham A.R. (2013), "Modelling human performance within an automotive engine assembly line", International Journal of Advanced Manufacturing Technology, Vol. 68 No. 14, pp. $141-148$

Zhao, X., Zhao, X. and Wu, Y. (2013), "Opportunities for research in behavioural operations management", International Journal of Production Economics, Vol. 142, pp. 1-2. 
TABLES

Table I. Inclusion and exclusion criteria for the studies reviewed

\begin{tabular}{|c|c|c|}
\hline 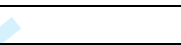 & Inclusion Criteria & Exclusion Criteria \\
\hline Population & $\begin{array}{l}\text { Discrete-Event Simulation } \\
\text { Hybrid models of discrete-event } \\
\text { simulation and other methods } \\
\text { where the DES element incorporates } \\
\text { human behaviour } \\
\text { Specific modelling of human } \\
\text { behaviour in OM }\end{array}$ & $\begin{array}{l}\text { 1. Irrelevance of content } \\
\text { - Other simulation methods } \\
\text { such as agent-based } \\
\text { simulation and system } \\
\text { dynamics } \\
\text { - Human's treated as a } \\
\text { process element } \\
\text { Other aspects of people } \\
\text { such as disease } \\
\text { transmission, physical } \\
\text { aspects. }\end{array}$ \\
\hline & & $\begin{array}{l}\text { 2. Duplication of content } \\
\text { - Duplication across search } \\
\text { databases } \\
\text { - } \quad \text { Duplication in later } \\
\quad \text { publication }\end{array}$ \\
\hline Outcomes & $\begin{array}{l}\text { Evidence of simulation model build } \\
\text { and results }\end{array}$ & $\begin{array}{l}\text { 3. Discussion of modelling human } \\
\text { behaviour but with no } \\
\text { simulation application }\end{array}$ \\
\hline & $\begin{array}{l}\text { Effect of study outcomes on system } \\
\text { performance }\end{array}$ & $\begin{array}{l}\text { 4. Effect of study outcomes on } \\
\text { operator performance }\end{array}$ \\
\hline Study Design & $\begin{array}{l}\text { Papers must be in English and } \\
\text { accessible }\end{array}$ & $\begin{array}{l}\text { 5. Papers not in English and } \\
\text { inaccessible }\end{array}$ \\
\hline
\end{tabular}


Table II. Articles reporting on the use of discrete-event simulation to model people's behaviour [2005-2017]

Ajaefobi, J., Weston, R., Wahid, B., Rahimifard, A. (2010)

Brailsford, S.C., Harper, P.R., Sykes, J. (2012)

Colombi, J.M., Ward, J.R. (2010)

Dode, P., Greig, M., Zolfaghari, S., Neumann, W.P. (2016)

Dubiel and Tsimhoni (2005)

Elliman, T., Eatock, J. and Spencer, N. (2005)

Hannah, S.D. and Neal, A. (2014)

Ilar, T.B.E. (2008)

Kazmierczak, K., Neumann, W.P. and Winkel, J. (2007)

Khali, S.N., Weston, R.H., Ajaefobi, J.O. (2009)

Knight, V.A., Williams, J.E. and Reynolds, I. (2012)

Kokkinou, A. and Cranage, D.A. (2011)

Kozine, I. (2007)

Lassila, A.M., Saad, S.M., Perera, T., Koch, T., Chrobot, J. (2005)

Majid, M.A. and Herawan, T. (2013)

Malachowski, B. and Korytkowski, P. (2016)

Mason, S., Baines, T., Kay, J.M., Ladbrook, J. (2005)

McHaney, R.W. (2008)

Nehme, C.; Crandall, J.W.; Cummings, M.L. (2008)

Nembhard, D.A. (2014)

Neumann, W.P. and Medbo, P. (2009)

Neumann, W.P. and Medbo, P. (2017)

Perez , J., de Looze, M.P., Bosch, T., Neumann, W.P. (2014)

Plott, B. (2006)

Riedel, R., Mueller, E., von der Weth, R., Pflugradt, N. (2009)

Robinson (2015)

Shewchuk, J.P., Nussbaum, M.A., Kim, S., Sarkar, S. (2017)

Silva, E. , Donauer, M. , Azevedo, A , Pecas, P. , Henriques, E. (2014)

Wang Q. , Sowden M. , Mileham A.R. (2013) 
Table III. Methods of modelling people's behaviour by modelling area and modelling approach

Arrivals

Movement

\begin{tabular}{|c|c|c|c|}
\hline \multirow{2}{*}{ MODELLING } & \multicolumn{3}{|c|}{ MODELLING APPROACH } \\
\hline & Scenario & Impact & Individual \\
\hline $\begin{array}{l}\text { AREA } \\
\text { Decision }\end{array}$ & & & \\
\hline & (Hannah 2014) & Equation & \\
\hline & Empirical & 2014) & \\
\hline & (Majid, 2013) & Empirical & \\
\hline & & (Majid, 2013; Elliman, 2005) & \\
\hline Availability & $\begin{array}{l}\text { Empirical } \\
\text { (Neumann, 2009) }\end{array}$ & $\begin{array}{l}\text { Distribution } \\
\text { (Lassila, 2005) }\end{array}$ & $\begin{array}{l}\text { Empirical } \\
\text { (Neumann, 2009) }\end{array}$ \\
\hline Task & Empirical & Distribution & Empirical \\
\hline & (Kazmierczak, 2007; Ilar, 2008; & (Mason, 2005; Kozine, 2007; & (Kazmierczak, 2007; Ilar, 2008; \\
\hline & Ajaefobi, 2010; Malachowski, & Perez, 2014; Shewchuk, 2017; & Wang, 2013; Ajaefobi, 2010; \\
\hline & 2016) & Neumann, 2017) & Malachowski, 2016) \\
\hline & Distribution & Equation & Distribution \\
\hline & (Kozine,2007; Silva, 2014; & (Colombi, 2010; Nehme, & (Silva, 2014; McHaney, 2008) \\
\hline & McHaney, 2008) & 2008; Dode, 2016) & Equation \\
\hline & Equation & Empirical & (llar, 2008; Wang, 2013; \\
\hline & $\begin{array}{l}\text { (Colombi, 2010; Nehme, 2008; } \\
\text { llar.2008: Khalil. 2009. }\end{array}$ & (Plott, 2006) & $\begin{array}{l}\text { Malachowski, 2016; Nembhard, } \\
\text { 2014) }\end{array}$ \\
\hline & $\begin{array}{l}\text { Malachowski, 2016, Neumann, } \\
\text { 2017) }\end{array}$ & & $\begin{array}{l}\text { Cognitive } \\
\text { (Riedel, 2009) }\end{array}$ \\
\hline Arrivals & & $\begin{array}{l}\text { Equation } \\
\text { (Knight, 2012) }\end{array}$ & $\begin{array}{l}\text { Cognitive } \\
\text { (Brailsford, 2012) }\end{array}$ \\
\hline Movement & & $\begin{array}{l}\text { Empirical } \\
\text { (Dubiel, 2005) } \\
\text { Equation } \\
\text { (Robinson, 2015) }\end{array}$ & \\
\hline
\end{tabular}


Figure 1.

PRISMA flow diagram illustrating the literature review process 
Figure 2.

Modelling people's behaviour using discrete-event simulation by year 


\section{Figure 3.}

Approaches to modelling people's behaviour using discrete-event simulation

People considered in terms of impact on task and organisational variables

Data collected on impact variables e.g. task importance, customer queue size
People considered as

\section{INDIVIDUAL} individuals (across) or over time (within)

Data collected on individual behaviour 


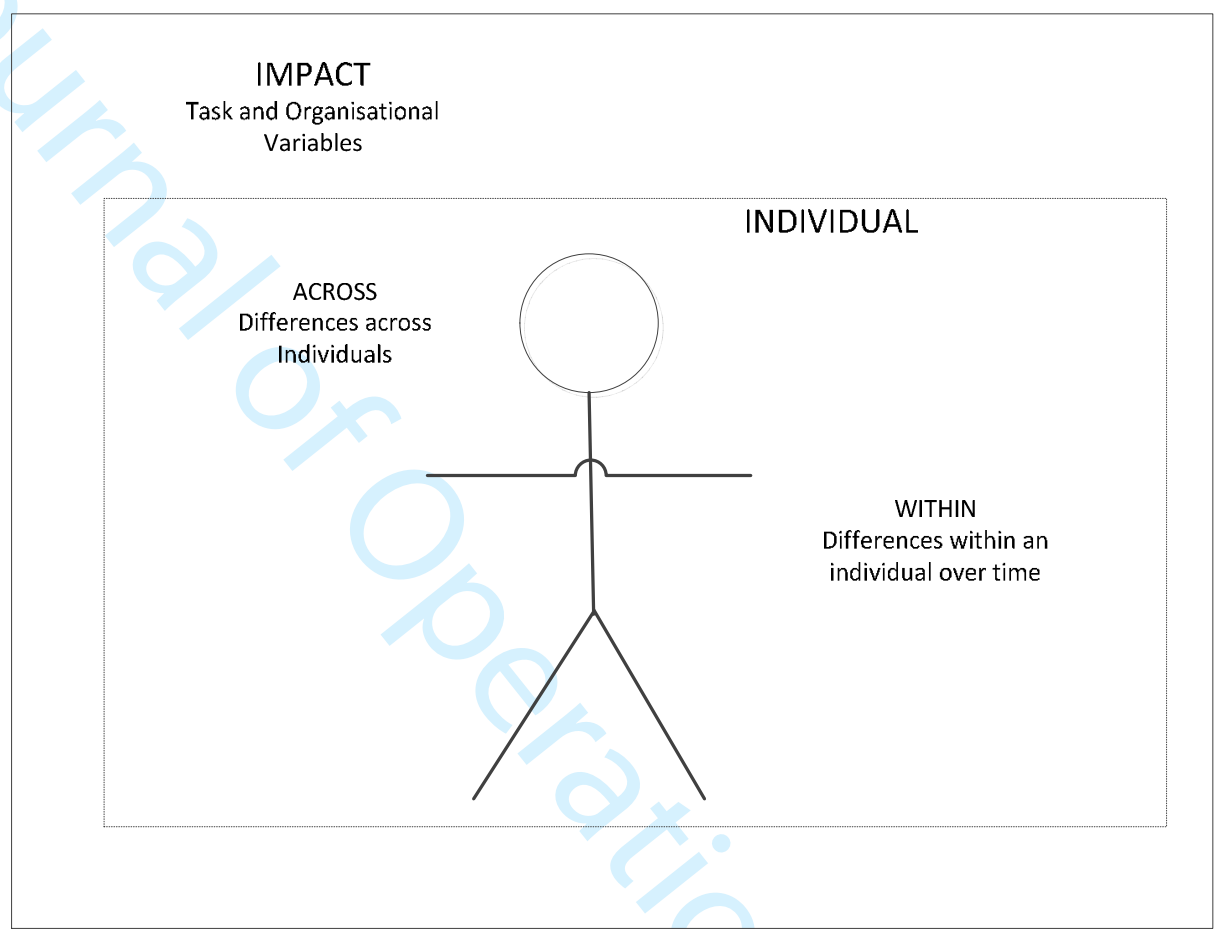

Figure 4.

Modelling people's behaviour 'inside' the model by impact and individual approaches 


\section{MODELLING PEOPLE'S BEHAVIOUR}

\section{SIMULATION STUDY METHODOLOGY}

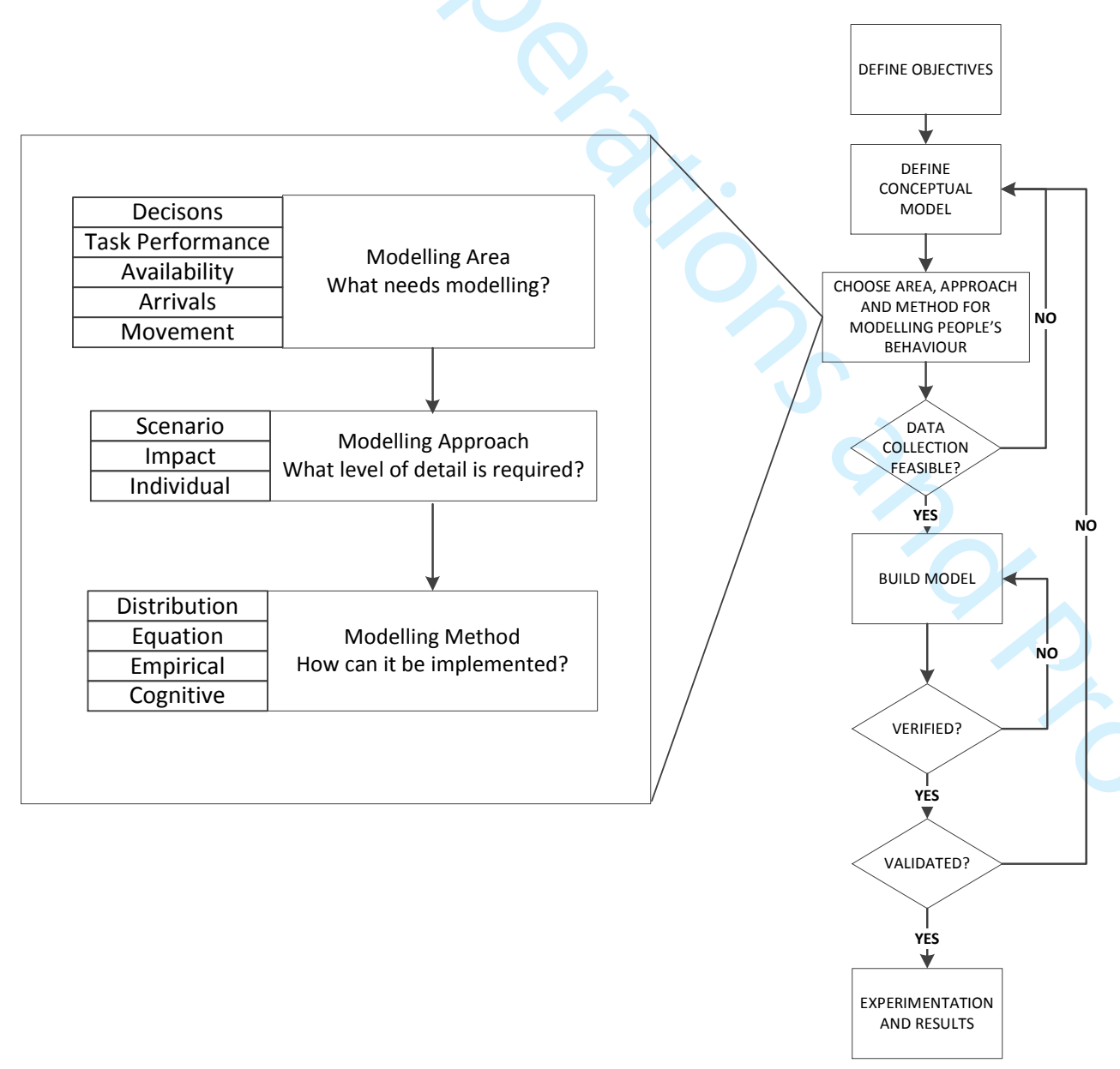

Figure 5.

A methodology for modelling people's behaviour in discrete-event simulation 